\title{
Changing pattern of birth weight over a decade in rural India
}

\author{
Vidyadhar B. Bangal*, Satyajit P. Gavhane, Swati D. Gagare, Kunal H. Aher, \\ Dhruval K. Bhavsar, Priyanka R. Verma
}

Department of Obstetrics and Gynecology, Rural Medical College, Pravara Institute of Medical Sciences, Loni, Maharashtra, India

Received: 11 August 2017

Accepted: 09 September 2017

\section{*Correspondence:}

Dr. Vidyadhar B. Bangal,

E-mail: vbb217@rediffmail.com

Copyright: (C) the author(s), publisher and licensee Medip Academy. This is an open-access article distributed under the terms of the Creative Commons Attribution Non-Commercial License, which permits unrestricted non-commercial use, distribution, and reproduction in any medium, provided the original work is properly cited.

\begin{abstract}
Background: Birth weight is one of the important determinants of neonatal wellbeing. Birth weight has many determinants that mainly include maternal nutritional status and the term of gestation. Low birth weight is associated with high neonatal and childhood mortality and morbidity. Over the years the birth weight is showing the increasing trend in developing countries like India. The study aimed at finding out the changing pattern of birth weight over a decade in rural India.

Methods: A retrospective analysis of over 45,000 births that took place in Tertiary care hospital from year 20082017was undertaken. The socio economic determinants of birth weight were studied.

Results: The incidence of low birth weight declined from 47 percent to 35 percent over ten years. The mean rise in birth weight in ten years was observed in both male (176 grams) and female (151grams).The incidence of very low birth and extremely low birth was found declined. There was positive co relationship between improved birth weight and improved socio economic status, delay in age at marriage, higher maternal weight gain during pregnancy, improved pre pregnancy nutritional status of women.

Conclusions: There is steady decline in incidence of low birth weight over last ten years in study area. Improved maternal health, better nutrition, improved quality of antenatal care and various efforts and actions from the government side have contributed in improving the birth weight.
\end{abstract}

Keywords: Antenatal care, Birth weight, Low birth weight, Maternal health, Maternal nutrition

\section{INTRODUCTION}

Birth weight of a newborn indirectly reflects mother's health and nutritional status. It also gives fair idea about baby's chances for survival, growth, long-term health and development. ${ }^{1}$ According to UNICEF, low birth weight pose grave health risks for children. It is a public health problem in developing and underdeveloped countries; globally an estimated $15 \%$ of births result in low birth weight babies. Babies who are undernourished in the intrauterine life face a greatly increased risk of dying during their early period of their life. Children born underweight also tend to have cognitive disabilities and a lower IQ, affecting their performance in school and their job opportunities as adults. India, one of the countries with the highest incidence of low birth weight, adds nearly 7.5 million such babies annually-the highest in any country. $^{2}$

Birth weight is one of the most important factor for estimating the maturity of the newborn, evaluating intrauterine growth and development. ${ }^{3}$ In both, the 
developed and developing countries low birth weight is the most important factor that affects perinatal mortality, neonatal mortality, infant mortality and infant and childhood morbidity. ${ }^{4}$ UNICEF has reported the $30 \%$ incidence of low birth weight in Bangladesh was, $26 \%$ in India, $21 \%$ in Pakistan and $25 \%$ in Sri Lanka. ${ }^{5}$ In India, NFHS reported that the proportion of low birth weight babies about $23 \%$ for rural and $19 \%$ for urban population. ${ }^{3}$ The proportion of low birth weight babies in Kerala was $18 \%$ in the year 1997. NFHS data showed that birth weight is influenced by many socio-economic factors like urban or rural, education, birth order, tobacco use by mother, wealth, religion and caste. ${ }^{3,6}$ Present study was carried out to observe the changing pattern of birth weight of newborns in rural area over ten years and to find out possible reasons for the change.

\section{METHODS}

Retrospective observational study was carried out at Pravara Rural Hospital. Data related to birth weight of newborn babies for ten years duration, from July 2008June 2017 was collected and analysed. Data was collected from labour room record and medical record section of Pravara Rural Hospital, Loni.

Pravara Rural Hospital is a multi-speciality 1275 bedded tertiary care teaching hospital, situated in rural area of Ahmednagar District in Maharashtra. India. The hospital is providing maternal health care and services since last 40 years and has good reputation in the area. Majority of high risk and complicated obstetric cases are referred to this hospital for specialist management. Hospital provides 24 hours maternity and neonatal care services. It has a well-equipped operation theatre and intensive care facilities and state of art neonatal care unit facilities. Approximately 8500 deliveries take place in the hospital per year. There has been exponential rise in the number of deliveries in last ten years. The women who avail services are predominantly from middle and lower socio economic class with low educational status.

The practices of early marriages are still prevalent in the area. Major intervention that took place in the villages and communities in the study population was in the form of implementation of "SIDA Project". It was a Multisectoral health and developmental project, implemented in 235 underserved and tribal villages of the same area of Ahmednagar district of Maharashtra, India for the period of four years (2006-2009). Two hundred sixty five trained female health volunteers (FHVs) and TBA's received structured training and were equipped with disposable delivery kits (DDKs).

The nine rural health centers (RHCs) and five mobile clinics (MCs) were established in the project area. A referral linkage was developed between villages and a tertiary care centre. This intervention was influenced by Swedish nurse-based health care. A baseline survey and end line survey was conducted before and after the intervention. The intervention included education program for project staff working in health facilities and those who were engaged in community level health activities. Health records and manuals, and informational and educational materials were produced and the clinics were equipped with easily handled instruments. The nurses were adequately trained to record birth weight using UNICEF infant weighing machine (lever balance type) to the nearest' $20 \mathrm{~g}$ after correcting the zero error. All the babies are weighed immediately after delivery. The weighing machines are being checked periodically and standardized.

The study included all live born babies irrespective of their gestational age or multi-fetal gestations. Data related to socio economic determinants of birth weight, obstetric problems, medical problems during pregnancy, maternal weight gain was gathered from case records. Relevant data of ten years duration was collected, cleaned, compiled, analysed and interpreted as per study objectives. Data was analysed using SPSS version 21.

\section{RESULTS}

It was observed that 45,120 babies were born during study period at Pravara Rural hospital. There was increase in number of deliveries by six times in ten years study period. The percentage of babies born with low birth weight was $47.19 \%$ in year 2008 and this percentage dropped down to $35.11 \%$ in year 2017 (Table 1).

Table 1: Year-wise birth weight distribution of newborn.

\begin{tabular}{|c|c|c|c|c|}
\hline \multirow{3}{*}{ Year } & \multicolumn{4}{|c|}{ Birth weight of Newborn } \\
\hline & \multicolumn{2}{|c|}{ Below 2500 grams } & \multicolumn{2}{|c|}{ Above 2500 grams } \\
\hline & $\begin{array}{l}\text { No of } \\
\text { babies }\end{array}$ & $\%$ & $\begin{array}{l}\text { No of } \\
\text { babies }\end{array}$ & $\%$ \\
\hline 2008 & 666 & 47.19 & 734 & 52.81 \\
\hline 2009 & 1520 & 45.83 & 1796 & 54.17 \\
\hline 2010 & 1690 & 41.88 & 2345 & 58.12 \\
\hline 2011 & 1967 & 40.29 & 2914 & 59.71 \\
\hline 2012 & 2491 & 40.27 & 3694 & 59.63 \\
\hline
\end{tabular}

Table 2: Mean birth weight change over a decade.

\begin{tabular}{|lll|}
\hline Year & $\begin{array}{l}\text { Mean Birth } \\
\text { Weight in grams } \\
\text { (Male) }\end{array}$ & $\begin{array}{l}\text { Mean Birth } \\
\text { Weight in grams } \\
\text { (Female) }\end{array}$ \\
\hline 2008 & 2546 & 2465 \\
\hline 2017 & 2722 & 2616 \\
\hline Change & $\begin{array}{l}\text { Rise in birth } \\
\text { weight by 176 } \\
\text { grams }\end{array}$ & $\begin{array}{l}\text { Rise in birth weight } \\
\text { by 151 grams }\end{array}$ \\
\hline
\end{tabular}

The mean birth weight of male and female babies born in year 2008 was 2546 grams and 2465 grams respectively. The mean birth weight of male and female babies born in 
year 2017 was 2722 grams and 2616 grams respectively. The mean birth weight for male and female babies increased by 176 grams and 151 grams respectively during study period (Table 2).

Table 3: Differences in birth weight distribution over a decade.

\begin{tabular}{|lll|}
\hline $\begin{array}{l}\text { Birth weight } \\
\text { distribution }\end{array}$ & $\begin{array}{l}\text { Year 2008 } \\
(\%)\end{array}$ & $\begin{array}{l}\text { Year 2017 } \\
(\%)\end{array}$ \\
\hline <1000 grams & 2 & 1 \\
\hline 1000-1500 grams & 7 & 4 \\
\hline 1501-2500 grams & 38 & 30 \\
\hline 2501-3000 grams & 43 & 49 \\
\hline >3000grams & 10 & 16 \\
\hline
\end{tabular}

The birth weight distribution showed that the number of babies born with extremely low birth weight $(<1000$ grams), very low birth weight $(<1500$ grams) and low birth weight got reduced over a period of ten years. Thus, the number of babies with birth weight of more than 2500 grams and also 3000 grams increased (Table 3).

Table 4: Socio economic class of pregnant women.

\begin{tabular}{|lll|}
\hline Socio-economic class by B. & Year & \\
G. Prasad Classification & $\mathbf{2 0 0 8}$ & $\mathbf{2 0 1 7}(\boldsymbol{\%})$ \\
\hline I & 43.00 & 49.00 \\
\hline II & 31.50 & 28.00 \\
\hline III & 18.50 & 16.00 \\
\hline IV & 5.50 & 6.50 \\
\hline V & 1.50 & 0.50 \\
\hline
\end{tabular}

There was improvement in the socio economic status of the women during the study period as assessed by Modified B G Prasad classification (Table 4).

It was observed that the average weight gain during pregnancy increased during over a period of decade. The percentage of pregnant women with weight gain of more than $10 \mathrm{~kg}$ increased from $14 \%$ to $23 \%$ (Table 5).

Table 5: Average weight gain during pregnancy.

\begin{tabular}{|lll|}
\hline $\begin{array}{l}\text { Weight gain } \\
\text { during pregnancy }\end{array}$ & Pear 2008 & Year 2017 \\
\hline$<5 \mathrm{Kg}$ & 2 & Nil \\
\hline $5-8 \mathrm{Kg}$ & 32 & 12 \\
\hline $8-10 \mathrm{Kg}$ & 52 & 65 \\
\hline $10-12 \mathrm{Kg}$ & 10 & 16 \\
\hline$>12 \mathrm{Kg}$ & 4 & 7 \\
\hline
\end{tabular}

Over a period of ten years, the average age at marriage for girls has increased from 16.52 years to 18.17 years. The age at first pregnancy has also increased from 18.50 years to 20.00 years (Table 6).
Table 6: Average age at marriage for pregnant women.

\begin{tabular}{|lll|}
\hline Year & $\begin{array}{l}\text { Average age at } \\
\text { marriage in years }\end{array}$ & $\begin{array}{l}\text { Age at first } \\
\text { pregnancy in years }\end{array}$ \\
\hline 2008 & 16.52 & 18.50 \\
\hline 2017 & 18.17 & 20.00 \\
\hline
\end{tabular}

Table 7: Pre pregnancy weight of pregnant women.

\begin{tabular}{|lll|}
\hline Weight in Kg & Year 2008 & Year 2017 \\
\hline $30-40$ & Percentage & Percentage \\
\hline $41-50$ & 12 & 06 \\
\hline $51-60$ & 53 & 40 \\
\hline $61-70$ & 28 & 36 \\
\hline Above 70 & 5 & 12 \\
\hline
\end{tabular}

Study revealed that the pre-pregnancy weight of women has shown significant improvement. The percentage of underweight $(<40 \mathrm{~kg})$ has reduced from $12 \%$ to $6 \%$. It was also noticed that the percentage of women with over weight $(>60 \mathrm{Kg})$ has increased from $2 \%$ to $6 \%$ (Table 7 ).

\section{DISCUSSION}

The present study was carried out at a tertiary care hospital, which caters to the needs of the rural community in central India. There is very high incidence of nutritional anaemia and overall under-nutrition in the study population. There is tradition of early marriages resulting into teenage pregnancies. Under-nourished teenage pregnant women give birth to underweight children. In addition to the very high incidence of nutritional anaemia, there is high incidence of pregnancy induced hypertension, which is one of the commonest reasons for intrauterine growth restriction. There is high incidence of lower genital tract infections and urinary tract infections. Both these factors give rise to preterm labour with or without premature rupture of membranes. Thus prematurity, Intra uterine growth restriction is the fetal causes that influence the incidence of low birth weight. Maternal under-nutrition, anaemia, hypertension, urinary tract infections, and lower genital tract infections affect the fetal growth and term of gestation, when the baby is born.

Over the years, the things have changing in right direction. There is overall improvement in maternal health and thus the outcome of pregnancy. Girls are getting better attention from the parents as compared to past They are being equally treated as sons, unlike few decades back. The girls education has received equal attention as boys. Community has understood the importance of female literacy. The gender bias is reduced. Things are more obvious in urban areas as compared to rural areas. Girl's education has positive influence on delaying the age of marriage and thus 
reduction in teenage pregnancy and its antecedent complications.

In the present study, it was observed that over a decade, the mean birth weight has increased. The increase is seen in both male and females. The rise in weight is more in males than females.

The community has realised the importance of small family norm and the limitation of child birth, spacing between two pregnancies and use of contraceptives. This has resulted in better health of pregnant woman, and her physical and mental preparedness to have another child. The improved awareness about good nutrition during pregnancy has contributed in good maternal weight gain during pregnancy and thus improved the fetal transfer of essential nutrients during intrauterine life. The improvement in per capita income, has improved the spending on nutrition and health. The government has understood their role in improving the maternal and child health services and have implemented many health schemes in last decade. This has also contributed in improving the maternal health and ultimately fetal health. In the present study, it was observed that the maternal weight gain has improved in last ten years. There is positive co relationship between maternal weight gain and birth weight. Same holds true for the socio economic class. Women with lower socio economic class give birth to undernourished children with resultant high perinatal, neonatal, infant and under-five mortality and morbidity. There is improvement in economic condition of rural population, with resultant improved spending on health and nutrition. This has improved the maternal health and resultant improved birth weight.

Present study revealed that the incidence of low birth weight has significantly reduced by 12 percent in last ten years. The incidence of extremely low birth weight and very low birth weight has reduced. The average birth weight is increased in both sexes, more in male as compared to females. The rise is significant and should be considered as a welcome sign. Multiple factors as discussed above, have resulted in reduction of incidence of low birth weight. The incidence of babies with higher birth weight of more than 3000 grams is significantly increased. The babies are much healthier than before. The healthy babies have better immunity and better start of the life. They have less morbidity and are less prone for development of common infections like pneumonia and diarrhoea. The overall morbidity and mortality of healthy babies is much less than underweight babies.

With the primary mission to improve the health of women and children, the government of India has set up the ministry of Women and Child development nearly four decades ago. The scope and activities of Integrated child development scheme (ICDS) has been expanded to cover pregnant women and adolescent and teenage girls. The nutritional supplement programmes with the help of international agencies have helped to improve the nutritional status of pregnant women and adolescent girls. Various maternal health related schemes under National Health Mission (NHM-Rural and urban) have also contributed in improved weight gain during pregnancy and thus improved birth weight of newborn babies.

Low birth weight stems primarily from poor maternal health and nutrition, poor nutritional status before conception, short stature (mostly due to under-nutrition and infections during childhood) and poor nutrition during pregnancy. Key interventions to prevent low birth weight include improved food intake for pregnant and lactating mothers, micronutrient supplementation, preventing and treating diseases such as malaria and HIV/AIDS, educating girls and expectant mothers, deworming primary school girls (future mothers) and preventing teenage pregnancies (underage mothers result in underweight babies).

There is no much published literature on the long term trend in the pattern of birth weight in India. The present study included more than 45000 babies and thus is one of the large studies on the subject. Few institutional studies in India and abroad have published their findings.

TM Celine and Jimmy Antony ${ }^{7}$ in their study titled "Pattern of Birth Weight of New Born Babies at a Tertiary Care Level" conducted during the period from $2000-2009$, the proportion of birth weight $(\geq 2.5 \mathrm{~kg})$ of new born babies was $80.8 \%$, low birth weight $(<2.5 \mathrm{~kg})$ of new born babies was $19.2 \%$. Of the new born babies, proportion of very low birth weight $(<2 \mathrm{~kg})$ was $6.9 \%$. In this study, sex wise difference in the proportion of low birth weight new born babies was not significant. But, significant difference occurred in the proportion of newborn babies with weight $\geq 2.5 \mathrm{~kg} \quad(\mathrm{p}=0.0001)$. It indicates that the proportion of males with weight $\geq 2.5 \mathrm{~kg}$ was more compared to females. The proportion of low birth weight of new born babies from 2000-2001 to 20082009 was increased from $17.8 \%$ to $25.09 \%$ ( $p<0.0001$ ). At the same time, the proportion of new born babies with weight $\geq 2.5 \mathrm{~kg}$ was decreased from 82.2 to $69.8 \%$ $(\mathrm{p}<0.0001)$.

Akoijam BS et $\mathrm{al}^{8}$ in their study titled "Birth weight pattern in the only referral teaching hospital in Manipur" reported that the birth weight was increasing with the passing years. The cross sectional study was attempted to see the birth weight pattern in the largest referral hospital in Manipur. Birth weights of four reference years in the last 15 years were extracted from the records and analysed. There were 19478 singleton deliveries in the four reference years. The mean birth weight showed a gradual increase in these years. There was a gain of 88.9 $\mathrm{g}$ in 2000 since 1986 in term deliveries. There were significant differences in the mean birth weights among the four years, even after stratifying for gestation. However, there was no significant decrease in the percentage of low birth weight babies in these years. Low birth weight showed significant association with parity, 
age of the mother, booking status, haemoglobin level, and literacy of the mother. Since there was no significant decrease in low birth weight babies in spite of increasing birth weight, there was a need for continued and committed effort to realize the goals of $\mathrm{RCH}$.

Prasad et al in their study -Birth Weight Pattern in Karnataka, reported the overall mean birth weight of $2823.6 \pm 417.8$ g. ${ }^{9}$ The mean birth weight in their study was 500 grams and 700 grams less than that of average birth weight of the American and European counterparts, respectively ${ }^{1}$. However, it was comparable to the studies conducted by ICMR and Dutta et al. ${ }^{10,11}$ Although the observed difference between mean birth weight of males and females was only $55 \mathrm{~g}$, it was found to be statistically significant $(\mathrm{p}<0.001)$.

The mean birth weight among the teenage and primipara mothers in their study was higher compared to other reports. ${ }^{10,12,13}$ This was attributed to better utilization of quality $\mathrm{MCH}$ care which were readily accessible to the beneficiaries. The preterm babies were lighter (mean birth weight $2087.5+353.0 \mathrm{~g}$ ) compared to term babies (mean birth weight $2875.9+353.6 \mathrm{~g}$ ). The trend of increase in mean birth weight with increase in gestational age was also observed by others. ${ }^{12}$

Teshome et al conducted a prospective descriptive study titled a study on birth weight in a teaching-referral hospital, Gondar, Ethiopia. ${ }^{14}$ It was carried out to determine the pattern of birth weight of neonates in a teaching-referral hospital and to identify some epidemiological parameters associated with them. Data in 810 consecutive hospital births were recorded. The mean birth weight of 373 full term singleton neonates was 3 003g (SD600). The incidence of low birth weight (birth weight $<2500 \mathrm{~g}$ ) and very low birth weight (birth weight $<1500 \mathrm{~g}$ ) was $15.4 \%$ and $2.6 \%$ respectively.

The mean birth weight and percentage of low birth weight were significantly different in both sexes $(\mathrm{p}<0.0001)$. The birth weight increased as parity and length of gestation increase. As maternal age and maternal height increased, so do the birth weights of their neonates. Total house hold income, maternal education and antenatal care use were not found to influence the mean birth weight in this study. Study concluded that the mean birth weight and prevalence of low birth weight were similar to other reports from Ethiopia. It was observed that as maternal age, maternal height, parity and length of gestation increased, the mean birth weight increased.

\section{CONCLUSION}

Normal birth weight is the birth right of a newborn. Good birth weight gives baby a good start to life and plays an important role in its optimum neonatal growth, development and protection from disease morbidity and mortality. Birth weight has various determinants like maternal health status, her constitution, presence or absence of medical and obstetric diseases that determine the fetal weight, term of gestation etc. Study revealed that there has been improvement in the birth weight in India and the incidence of low birth weight is decreasing. Overall improvement in socio economic status, health awareness, maternal nutrition, quality antenatal care and provisions of various government schemes like NRHM have helped to improve the pregnancy outcome in the form of reduction in low birth weight and reduced perinatal morbidity and mortality. Continuous efforts in the same direction will further reduce the gap in incidence of low birth weight between developed and developing countries.

\section{ACKNOWLEDGEMENTS}

Authors acknowledge the Centre for Social Medicine and Pravara Institute of Medical Sciences (Deemed university) for the support in publication of this study.

Funding: No funding sources

Conflict of interest: None declared

Ethical approval: The study was approved by the Institutional Ethics Committee

\section{REFERENCES}

1. Kramer MS. Determinants of low birth weightMethodological assessment and meta analysis. Bull WHO. 1987;65:663-737.

2. New Trends and Approaches in the Deli- vol31 1994 very of Maternal and Child Health Care in Health Services. Geneva, WHO Publication, TRS No. 1978;60072-98.

3. Bhattachariee B. Study on birth weight in Azimpur MCH training institute and Sir Salimullah Medical College and Hospital during February-March, 1983. Dissertation of DMCH and FP. Bangladesh:National Institute of Preventive and Social Medicine (NIPSOM), Dhaka University 1212.

4. Begum MR, Bhuiyan AB, Khanom ST. Incidence of low birth weight babies in Dhaka Medical College hospital, Bangladesh. J Obstet Gynecol. 1995;101:26-37.

5. United Nations Children's Fund, The State of the World's Children 2004: Girls, education and development. Newyork:UNICEF;2003: 20.

6. Radhakrishnan T, Thankappan KR, Sarma PS. Socioeconomic and demographic factors associated with birth weight. Results of a community based study in Kerala (1997) India. Trivandrum, India: Achutha Menon Centre for Health Science Studies.

7. Celine TM, Antony J. Pattern of birth weight of new born babies at a tertiary care level. Int J Prev Med. 2012;3(5):375-6.

8. Akoijam BS, Thangjam ND, Singh KT, Devi SR, Devi RK. Birth weight pattern in the only referral teaching hospital in Manipur. Indian J Public Health. 2006;50(4):220-4. 
9. Prasad KN, Rao RS, Sujatha A. Birth weight pattern in Karnataka. Indian Pediatr. 1994;31(7):836-9.

10. Dutta Banik ND, Krishna R, Mane SIS. A study of birth weight of Indian infants and its relationship to sex, period of gestation, maternal age, parity and socioeconomic classes. Indian $\mathrm{J}$ Med Res. 1967;55:1978.

11. Nutritional Atlas of India, Indian Institute of Nutrition (ICMR), Hyderabad, India;1971:34-56.

12. Mukherjee S. Birth weight in relationship to gestation, age, sex and other maternal factors. J Indian Med Assoc. 1959;32:389-97.

13. Das KG, Saha R. Interrelationship of birth weight with certain biological and socioeconomic factors. Indian J Pub Health. 1981;25:11-9.
14. Teshome D, Telahun T, Solomon D, Abdul hamid I. A study on birth weight in a teaching-referral hospital, Gondar, Ethiopia Central Afr J Med. 2006;52(1-2):8-11.

Cite this article as: Bangal VB, Gavhane SP, Gagare SD, Aher KH, Bhavsar DK, Verma PR. Changing pattern of birth weight over a decade in rural India. Int J Reprod Contracept Obstet Gynecol 2017;6: 4625-30. 